\title{
The Usage of Social Media in Engaging Youths in Agricultural Development in the Federal Capital Territory, Abuja, Nigeria
}

\author{
Alabi, T $^{*}$, Nnaji, N, J. (PhD) $)^{2}$ \\ ${ }^{1 *}$ Department of Sociology, University of Abuja, Abuja, Nigeria \\ ${ }^{2}$ Department of Agricultural Economics and Extension, University of Abuja, Abuja, Nigeria
}

*Corresponding Author: Alabi, T, Department of Sociology, University of Abuja, Abuja, Nigeria

\begin{abstract}
This study was carried out to assess the usage of social media in engaging youths in agriculture in the Federal Capital Territory, Abuja as a solution to youth engagement in agriculture and unemployment problems in Nigeria. The broad objective of this study was to assess the usage of social media in engaging the youths in agricultural development in the Federal Capital Territory, Nigeria. Also other specific objectives include: ascertain the type of social media platforms that are mostly used by youths in agriculture for accessing agricultural information in the study area; ascertain various benefits of social media in farm activities; and identify the challenges encountered by youth farmers in the use of social media for agricultural information among youth in agriculture. A sample of three hundred and sixty youths in agriculture was randomly selected through the multi-stage sampling techniques in the study area. The instruments used for data collection were questionnaire and focused group discussion (FGD). The utility theory was adopted for the study. The data was analyzed using descriptive statistics and log it regression model. Data were analysed using Statistical Packages for Social Science (SPSS). Results of the log it regression analysis carried out to establish the social-economic factors that significantly influence the usage of social media by youth in agriculture showed that the independent variables studied accounted for a co-efficient of multiple determination of $0.510(51.0 \%)$. The findings revealed that the youths in agriculture accessed one or more social media platform and the mostly used social media platform among the youths in agricultural in the study area is whats App (23.7\%).The findings also revealed that youths in agriculture benefitted from using social media to acquire agricultural information. Among the most common constraints faced by youths in the study area were: poor electricity, high cost of computer, no Internet and power outages. The findings recommended the need to incorporate agricultural information packages on social media platforms. Also, social media platforms should be deployed by agricultural service providers as part of their communication plan in promoting youth's participation in agriculture.
\end{abstract}

Keywords: Social media, agriculture engagement youths and employment

\section{INTRODUCTION}

Agriculture is the engine of growth for most developing countries like Nigeria and agricultural development is one of the most effective ways to alleviate hunger and poverty in a country (Amungwa and Baye, 2014).Agriculture has remained one of the top and widely profitable business sectors not only in Nigeria but in the world at large (Adelanke, 2019). It provides employment opportunities for the teeming population, eradicates poverty and contributes to the growth of the economy (Agwu, Nwankwo and Anyanwu, 2014). Of all the sectors of the Nigerian economy, agriculture possesses the greatest potential for playing a leading role in making Nigeria a self-reliant nation. This is true because agriculture provides food, employment opportunities, earns foreign exchange and generates considerable revenue for Nigeria (Anaeto, Asiabaka and Okoroma, 2015).Thus, the importance of the agricultural sector in generating employment and stimulating overall economic development in a developing country such as Nigeria cannot be undermined (Ogbalubi and Wokocha, 2013).

In spite of the agricultural sector's vibrancy in providing income-generating opportunities for youth, agriculture is still left to the elderly or uneducated youths (Okiror and Otabong, 2015). This has led to decline in agricultural output and the overall contribution of the sector to the economy and affected Nigeria's perception of the place and role of agriculture in national development considerably over time (Adigun, Bamiro and Oyetoki,2017).As a result, achieving a balance between food and population growth is a serious problem in Nigeria today in Nigeria (Anaeto, Asiabaka, and Okoroma, 
2015). The youths, however, need to be involved in agriculture in order to ensure continuity in occupation (Agumioagu, Ifeanyi and Agu, 2017). Youth participation in agriculture is definitely the only means to increase agricultural production and reduce unemployment rate in Nigeria (Adekoya, 2019).The youths have great potentials to drive forward the sector and also preserve it for posterity. They have the physical strength, mental alertness and innovations to embark on large scale agricultural activities (Jacob, Oshega and Ogri, 2017). However, the role of the youth as the next generation for the sustainability of the agricultural sector is very important (Susilowati, 2014). This calls for securing the interest and participation of youth in agriculture (Paisley, 2013). Exposure of youths to modern technologies that give them access to information from around the world is changing the perceived needs of young people, and this must be recognized especially by leaders, thus harnessing the opportunities and challenges thereof (Naamwintome and Bagson, 2013).

The evolution of Internet-based communication tools known collectively as "social media" has provided a visible solution to this challenge. Social media are a contemporary channel of digital communication that is composed of various evolving tools for discussion, interaction and sharing of information among people (Aliyu and Afrad, 2017).The main purpose of social media is sharing information, creating awareness and opportunities in agriculture. Social media can effectively empower the youths with information in agriculture and education that are capable of spurring them into agricultural or agro-based activities (Fabinu, 2014). Social media can be used to help better agriculture's image across a broad audience and allow for sharing of information and experiences between young people and young farmers (Young Professionals' Platform for Agricultural Research for Development(YPARD, 2017). Using social media for youth engagement can help organizations reach young people where they can be found online through search engines, communicate with young people in familiar settings and make ideas and opportunities accessible to other youth (Guanah, obi, Egbra, and Akumabor, 2017). This will enhance the introduction of modern extension and agricultural technologies and will increase extension coverage. The use of social media provides reliable markets and modern production information on existing livestock and crops thereby providing better access to profitable markets (Irungu, Mbugua and Muia, 2015). Therefore, the focus of this study is to assess the usage of social media in engaging youths in agricultural development in the Federal Capital Territory and how this can bring about development in the agriculture sector

\subsection{Objective of the Study}

The broad objective of this study was to assess the usage of social media in engaging the youths in agricultural development in the Federal Capital Territory, Nigeria with the aim of unraveling the most appropriate platform to be deployed by agricultural information providers to engage youths for agricultural development.

Specifically, this study was designed to:

1. ascertain the type of social media platforms that are mostly used by youths in agriculture for accessing agricultural information in the study area

2. ascertain various benefits of social media perceived by respondents in utilizing agricultural information in farm activities

3. identify the challenges encountered by youth farmers in the use of social media for agricultural information among youth in agriculture

\section{THE UTILITY THEORY}

The theory of utility serves as one of the theoretical frameworks for this study. The original concept of utility was developed principally by the moral philosopher, Jeremy Bentham (1747-1842) and John Stuart Mill (1806-1873) in the late eighteenth century and formally integrated into the analysis of economic problems by William Stanley Jevons (1835-1882) (Wikipedia, 2018). Utility theory is the perceived value (i.e. usefulness) an individual receives when purchase a good or service. Five types of economic utility which include form, place, time, possession and place were identified (Quickonomics, 2018).

Utility theory bases its beliefs upon individuals' preferences. It is a theory postulated in economics to explain behavior of individuals based on the premise that people can consistently rank order their 
choices depending upon their preferences. Each individual will show different preferences, which appear to be hard-wired within each individual. Utility theory is a positive theory that seeks to explain the individuals' observed behavior and choicesThe utility theory then makes the following assumptions: completeness, more-is-better, mix-is-better and rationality (Prakash, 2012).

Utility theory relates to this study because it centers on the perceived value (i.e. usefulness) and utility (satisfaction) which youths receive when they purchase and use social media for agricultural information. The social media can be used to create awareness and encourage the youths to participate in agriculture because of its attendant benefits (usefulness).Through the social media, the youth will be become better informed and educated by being constantly abreast of global news and information. This will enable the change agents, researchers, enthusiasts and professionals to identify the social platform which youths are interested in (or not interested in) in receiving agricultural information. It will open up a platform that agricultural extension officers, farmers, agricultural institutions and nongovernmental institutions utilize to disseminate and exchange agricultural information to youths in agriculture.

This theory is important to this study because it helped to determine the level of satisfaction derived from the usage of social media. The level of satisfaction with the usage of social media will largely facilitate the utilization of this source of information (social media). Social media have utility but only if they bring satisfaction to the youth. This theory can be found to be very useful to this paper because it provides a methodological framework for the evaluation of alternatives. This theory provides the youth with alternative platform from where they will make the best choice based on thehighest utility (satisfaction level).The attendant benefit (usefulness) will be determined by checking the relative satisfaction levels derived by individual youth when they access agricultural information from smart phone and Internet. But due to increasing number of social media platforms, the decision of choice is getting diverse for youth farmer and agricultural extension advisory service providers. By using this theory, Agricultural Extension advisory service could assist farmers to develop a receptive mine towards agriculture, there by improve extension service delivery to them on a given platform.Hence, extension agencies should also quickly adapt and develop relevant information, which can be disseminated through these tools. Youth farmers should explore the potentials and opportunities that social media can offer the youth of information and technology so that its benefits will be harnessed to the fullest.

The theory is important to this study because it helps to explain the "mix-is-better" assumption about preferences which says that a mix of the two is better than one i.e. the usage of more than two platforms of social media will be better than two. For example, the use of Whatsapp and Face book will be better than only Whatsapp. Youth in agriculture should be encouraged to open multiple accounts on the various social media platform. It will make it easy for them to collaborate and network with a larger audience.

\section{LITERATURE REVIEW}

\subsection{Benefits of Social Media to Farmers}

Guest (2015) present social media as the unique solution of connecting young farmers to opportunities in agricultural sector. Koyu, Singh, Kalai, Dabi and Das (2017) are of the view that social media create exposure to improve skill and technology acquisition to users hence, youths that engage in agricultural practices using social media could be in better position to learn new practices, connect to donners and technologies required for an enhanced production and sales.

Farmers and those interested in farming obtain information from social media platform. These platforms educate and inform them on agricultural matters as well as facilitate the buying and selling of agricultural produce and related products. The users exchange information and discuss issues concerning agriculture based on experience and knowledge. They also buy and sell agricultural produce and inputs and use pictures, links and videos to facilitate this. This sharing of information facilitates the marketing of the farmers produce and formation of networks. The social media platforms are also used to share links, news articles, information, feedback and for queries (Kipkurgat, Onyiego and Chemwaina, 2016).It provides farmers a quick and easy way to build relationships and interact with people in agriculture (Sulaman, Ogakaso and Faruk, 2018). 
Social media offers timely and reliable information as it has brought changes in the way farmers do their business especially in the rural communities. The use of social media saves costs by providing access to agricultural information through communicating with customers and other partners involved in agricultural processes. Social media opens new market opportunities, especially in situations of changing market prices, helps in the acquisition of fertilizers and pesticide information for pest and disease control (Adeyemi, 2012). Through social media rural dwellers are linked to the cities and the world at large, so that opens up a very convenient and effective medium to reach out to a wider audience. Hence it can be leveraged to disseminate important agricultural information and innovations as well as marketing outlet for their products (Muktar, Mukhtar and Ahungwa, 2015). Social media provides unlimited platform for genuine business transactions as it offers youth farmers with business acumen the opportunity to promote their goods and services for a global market. Through this, many have been delivered from the shackles of abject poverty (Fabinu, 2014).Social media plays a very important role in enhancing interactions and information flows among different actors involved in agricultural innovation and also enhance capacities of agricultural extension and advisory service providers. Agricultural programs planners are using social media to engage audiences and obtain feedback (Kipkurgatet al.,2016). Hence, agriculturists can no more rely on justface-to-face communication to tell their stories and to improve their trade. This is because social media has made communication easier (new media, 2015). The mindset of these youths could be positively channeled towards agricultural production with the application of social media. This will ultimately engage most of these sound minds and turn them away from crimes and other social vices (Kayode, Adedeji, and Agwu, 2015).

Lauren, Sarah and Dan (2014), explain different benefit of social media in agriculture as follows:

1. It can help create a unique voice. Social media allows the consumer to learn more about who a farmer is and what the farmer does. This can help the farmer stand out among the competition and build brand awareness. This is especially key for farmers who direct market their products. Social media is a great way to provide consumers with transparency and more information about what happens in the farm on a daily basis.

2. It can help connect farmers with new consumers and improve relationships with existing customers, i.e., direct buyers, restaurants, chefs, etc. These are people that the farmer would not have encountered otherwise. If a farmer has a website for his farm and produce, social media can be an excellent way to drive new people to your website or blog. Social media also offers a chance to obtain feedback about your operation and to learn more about what your target audience really wants. Social media as a business tool that can help identify new customers and boost your marketing outreach

3. It can help educate the public about a farmer's business. If a farmer raises pastured poultry, for example, it can allow him to explain to a larger audience why he thinks pastured poultry is beneficial. If the farmer is passionate about certain aspects of food production, like organics, he can use the social media platform to educate the population about organics and to establish himself as an authority on the subject.

4. It can help the farmer link up with other producers and agribusiness professionals. At its core, social media is a networking tool. Farming can be an isolating job at times. An unpredictable schedule or living in a rural area can make opportunities for socializing with other producers few and far between. Social media can provide a digital way to connect with other producers throughout Nigeria, or even abroad. Connecting with other farmers and perusing their social media pages can not only help one get inspiration for what to post on the page, it may help one learn new ways to improve the production side of your business.

5. It can help the farmer stay relevant among an increasingly digitalized market. Industry standards are changing when it comes to marketing, with more companies having social media accounts than companies who do not have. This is especially true in the food and agriculture industry. As more and more farms create social media accounts and use it as their primary way of communicating with customers and potential clients, consumers may prefer to choose a farm that has a social media presence over one that doesn't. 


\section{MAJOR FINDINGS}

\subsection{Types of Social Media Platform Used by the Respondents}

Table 2 revealed that majority of the respondents used WhatsApp chat (23.7\%) as their main platform to search for agricultural information. This implies that majority of the youth were familiar with social media site and used WhatsApp platform most for agricultural information. Thisindicates that youth farmers in FCT use their social media for agricultural information. Therefore, the study infers that WhatsApp is the most popular social media platform used among youths in agriculture in FCT Nigeria, and should be explored as a platform by extension, research institutes and other organizations to reach out to the youth in agriculture. The high usage of whatsApp can be explained to urge to get connected with their friends and relatives (Jisha and Jebakumar, 2014). The social media where youths in agriculture were least present include Twitters (1, $6 \%)$, Skype $(0.8 \%)$. Myspace $(0.8 \%$, ) Hangout $(0,6 \%)$. podcasts $(0.4 \%)$, Imo $(0.2 \%)$, Wikis $(0.2 \%)$, Research gate $(0.2 \%)$, Pinterest $(0.2 \%)$, Tumbler $(0.2 \%)$, Flicker $(0.0 \%)$ Flicker $(0.0 \%)$, Imo $(0.20 \%)$, Wikis $(0.2 \%)$, Reserchgate $(0.2 \%)$ and Tumbler $(0.2 \%)$. This could be as a result of the unpopularity of these social media platforms among the young farmers (Orifah, Ijeoma, Olajide, Olajide and Wigwe, 2017). Low usage of platforms such as, Linkedin, suggests that farmers hardly patronize professional and academic based media. However, this particular platform is relatively new to younger generations (Jasmine et al, 2016). The implication is that there is poor usage of these social media for searching for agricultural information by the respondents. This finding agrees with Suleiman, Ogakason and Faruk(2018); Bhalchandraand Deshmukh (2017)which revealed that majority of the respondents used WhatsApp platform most to seek agricultural information. On the contrary, the result disagrees with Khou and Suresh (2018) that showed YouTube the most commonly social media platform used among farmers in a study carried out on the role of social media mobile applications and its impact on agricultural marketing in the villages of Pooranakuppam, Manaveli, Thavalakuppam and Nallavadu under Puducherry region.

This was confirmed in interviews with the focused group, while responding to the questionas to the type of social media platforms that are mostly used by the youth in agriculture for accessing agricultural information?

"WhatsApp. It is popular and almost all of us have the App. It sends unlimited images, video and audio messages unlike twitter which is limited to 140 characters. This very platform helps us to conduct meeting online and exchange ideas, pictures, information and greetings among ourselves. "(Inferred from Focus Group Discussion)

Similar findings were recorded in focused group:

"WhatsApp is a popular platform. I fell happy using WhatsApp because it helps me to get in touch with friends, family and other farmers. We exchange vital information on this platform. It is a closed use group which has second level encryption and security.In fact, it is my best platform. But I also use YouTube, because I visualize things that are posted in the platform.

Table4.2. Social Media Platforms that are Mostly Utilized by Respondents $(N=180)$

\begin{tabular}{|l|l|l|}
\hline Social Media platform & Frequency & Percentage \\
\hline WhatsApp & 117 & 23.7 \\
Facebook & 48 & 9.7 \\
Blogs & 13 & 2.6 \\
Twitters & 8 & 1.6 \\
YouTube & 107 & 21.8 \\
Linkedin & 31 & 6.3 \\
Instagram & 14 & 2.9 \\
Snapchat & 15 & 3.1 \\
Pinterest & 1 & 0.2 \\
Research Gate & 1 & 0.2 \\
Flicker & 0 & 0.0 \\
Tumbler & 1 & 0.2 \\
Podcasts & 2 & 0.4 \\
Myspace & 4 & 0.8 \\
\hline
\end{tabular}


The Usage of Social Media in Engaging Youths in Agricultural Development in the Federal Capital Territory, Abuja, Nigeria

\begin{tabular}{|l|l|l|}
\hline \multicolumn{2}{|c|}{} \\
Google+ & 75 & 15.3 \\
Wikis & 1 & 0.2 \\
Skype & 4 & 0.8 \\
Email & 46 & 9.4 \\
Hangout & 3 & 0.6 \\
Imo & 1 & 0.2 \\
\hline
\end{tabular}

\subsection{Computed from Field Data, 2019*Multiple Responses.}

\subsubsection{Perceived Benefits of Social Media to the Respondents}

Table 3 showsthe benefits of social media use by respondents' agricultural practices The respondents showed positive response (agreed) to all the listed benefits of use of social media. The respondents improved in the following areas; new Crop Varieties $(\overline{\mathrm{X}}=2.33)$, with a standard deviation of .708 ; new farm input application methods $(\overline{\mathrm{X}}=2.11)$, with a standard deviation of .697 ; new market outlets $(\bar{X}=2.05)$, with a standard deviation of .619 ; loan availability $(\bar{X}=2.00)$, with a standard deviation of .770 ; fertilizer application $(\overline{\mathrm{X}}=2.09)$, with a standard deviation of .719 ; and weather condition $(\overline{\mathrm{X}}=$ 2.13), with standard deviation of .704. This implies that social media brings about the sharing of agricultural related ideas among farmers and proved immensely useful to farmers in communicating agricultural information in the study area. This agrees with Bhalchandra and Deshmukh (2017) who found out that farmers are making use of social media for innovative practices, sharing information etc on the Study carried out on Role of Social Media in Agriculture Marketing and its Scope. This result confirmed the finding of Khou and Suresh (2018) that most farmers in the villages of Pooranakuppam, Manaveli, Thavalakuppam and Nallavaduunder Pondicherry uses social media for agricultural purposes. This is supported by Kipkurgat, Onyiego and Chemwaina(2016) who revealed that social media is largely beneficial and convenient as a source of agricultural information. This also agrees with Suleiman, Ogakason and Faruk (2018) who revealed that farmers in the study area have access to social media platforms and use them to source agricultural information. They revealed further that social media has influenced farmer's participation in agriculture. Table 4.3 also indicates a standard deviation that is less than one showing that there is agreement with the various benefits of social media as reported by the respondents. This finding is in line with Adeyemi, (2017) who opines that farmers may use social media to acquire agricultural information. However, this showed that farmers are making their presence known online.

In response to the question in your opinion on the usage of social media "what are the perceived benefits involved in using social media, findings were realized from the focused group that:

"Social media gives us the opportunity to access agricultural information
including latest method of farming from other countries.Farmers are getting the
right information on the right time.it addresses problems faced by farmers to some
extent. It saves time and cost of the farmers for getting information and it is
making us proud. But we still need the help of extension officers to do better in the
usage of social media in agriculture." (Inferred from a Focus Group Discussion)

Focus Group Discussions also provided information that agrees with the above data. The discussants strongly indicated that social media could attract more youths to the sector.

Table3. Benefits of Social Media on Agricultural information to the Respondents

\begin{tabular}{|l|l|l|}
\hline Agricultural information & Mean & Std. Deviation \\
\hline I got information on new crop varieties & $2.33^{*}$ & .708 \\
\hline I got information on new breeds of animals & 1.94 & .803 \\
\hline I got information on new farm input application methods & $2.11^{*}$ & .697 \\
\hline I got information on new market outlets & $2.05^{*}$ & .619 \\
\hline I got information on loan availability & $2.00^{*}$ & .770 \\
\hline I got information on new feeding system for animals & 1.80 & .801 \\
\hline I got information on fertilizer application & $2.09 *$ & .719 \\
\hline I got information on high roofed greenhouse & 1.84 & .726 \\
\hline I got information on weather condition & $2.13 *$ & .704 \\
\hline I got information on buying location & 1.86 & .748 \\
\hline Valid N (listwise) & & \\
\hline
\end{tabular}

Computed from field data, 2019Agricultural Knowledge $\bar{X} \geq 2.00$

International Journal of Humanities Social Sciences and Education (IJHSSE) 


\section{CONCLUSION}

Agriculture is a key sector in most developing countries. However, there is a need to make agricultural information available and accessible to youthswho can drive the sector forward. The use of social media in agriculture increased opportunities, motivated and increased the capacity of the youth to engage in profitable agriculture targeting niche markets. Their usage among Nigerians is reported to be on the increase; hence, social media usage in agriculture will not only change their attitude toward agriculture but the mindset of these youths could be positively directed towards agricultural production with the application of social media. This will ultimately engage most of these sound minds and turn them away from crimes and other social vices, the application of social media into agriculture will keep most youths in the rural and urban areas as they will be gainfully employed leading to increase agricultural production in Nigeria. The study was aimed at boosting active youths' participation in agriculture, thereby enhancing the economic growth of the nation.

The outcome of this shows that: (a) Males were involved more than their females counterpart in the social media usage in the study area and this is the reasons for gender disparity in access to ICTs, (b) youths were using social media for accessing agricultural information and youths that were using social media engaged more in agriculture because they have access to agricultural information than their counterpart that do not use social media, (c) WhatsApp is the most commonly used social media platform among youth farmers in the study, (d)the notable benefits derived by youths via social media were new crop varieties, new farm input application methods, new market outlets, loan availability. fertilizer application and weather condition, (e)that social media helped to engage youth in agriculture through extension services, (f) Age, education farm experience, income and gender of the respondentssignificantly influence the usage of social media in agriculture in the study area. Therefore, these variables should be able to lend themselves into policy formulation/advice to increase social media usage by youths in Agriculture in the study area, and (g) Poor electricity was the most severe constraint. In this regard, this study has proved the fact that the social media, if given adequate attention will serve as a veritable and indispensable tool that will promote youth participation in agriculture and bring about sustainable development in the agricultural sector. Hence, this study established that social media can engage and promote participation in agriculture among youths in agriculture in Federal Capital Territory, Nigeria.

We hereby conclude that social media should be linked to agriculture. If possible service providers such as research institutes and extension services should utilize the social media platforms to reach out to youths in agriculture in order to improve information sharing and engage them in agriculture as well.

\section{RECOMMENDATIONS}

The usage of social media in agriculture, based on the above, is surely one of the ways the government can re-engage youths in agriculture and curb the rising unemployment problems in Nigeria. Therefore, based on the results of this study the following recommendations are made as a way of developing agriculture for greater youth participation in Nigeria:

i. Women have more constraints in gaining access to social media than their male counterparts.This is one of the reasons for gender disparity in access to ICTs. Women use social medialess compared to their male counterpart as reflected by the results of this research. The inequality in gender access to ICTs in the study area can be addressed by encouraging women youths to involve in social media usage in agriculturein order to enjoy the benefits of social media so as to help increase their participation and farm productivity

ii. Since the social media are the major platforms youth use for communication, government should encourage the use of social media as a means of communicating agricultural information to youths in Agriculture and youth agriculturalists in Nigeria so that the youths can tap the benefits of the social media. This will greatly helpto change the face of agricultural practice in the country and avoid being left out of global trends.

iii. WhatsApp is the most commonly used social media platform among youth farmers in the study area. Therefore, the use of whatsApp in agriculture should be expanded and widely popularized in agriculture 
iv. Gender, age, education, farming experience, and income were found to significantly influence the usage of social media in agriculture in the study area.These variables contributed positively to food production. This implies that as these variables increase the ability to use social media also increases. Therefore, these variables should be targeted, improved and addressed from time to time in order to further increase social media usage by youth in agriculture in the study area.

v. The use of social media is greatly influenced by education. Therefore, the educational curricular in agricultural science, animal husbandry and fisheries of subjects taught in secondary school should incorporate applications of information technology especially social media agriculture. Educating farmers with social media knowledge can generate innovative ideas and creativity for their productions and marketing of their produces. Since extension service can no longer reach large number of farmers, social media can be used to complement extension services in areas where there are geographically dispersed groups and where extension officers cannot effectively reach all farmers due to factors such as inaccessibility of roads.

vi. Poor electricity was identified as a major problem for accessing agricultural information from social media. The Nigerian government and other relevant agencies should maintain and expand electricity supply to communities so as to improve the level of social media usage among youths in agriculture.This will result in increased use of mobile phones for agricultural purposes.

vii. The study identified inability to buy social media tools as a major reason for not using social media. Based on this, cheaper versions of android and iphone that are user friendly should be provided to youth farmers instead of the old java phones to enhance efficient usage for engaging youth in agriculture

viii.Also, lack of awareness and skills to use social media tools constitute constraints to the use of Social Media usage among Youths in Agriculture. The Ministry of Agriculture and Extension organizations should organize training workshops to aid youth farmers improve their knowledge and application of social media platforms in agriculture so as to help improve efficiency among farmers. These constraints can be addressed through sensitization, awareness campaignsincluding training in order to promote maximum gain and utilization of technological knowledge and information which will lead to improved agricultural production, increased productivity as well as improved standard of living of the farmers.

\section{REFERENCES}

[1] Adelanke, A. (2019).19 Business Opportunities in Agriculture Sector in Nigeria. Retrieved on 17/03/2020 from https://infoguidenigeria.com/business-opportunities-agriculture-sector-nigeria/

[2] Adeyemi, A. A. (2017). Influence of Socio-Economic Factors On Farmers' Use of Mobile Phones for Agricultural Information in Nigeria.Pp $3-4$

[3] Adigun, G.T Bamiro O.M \&Oyetoki A. (2017). Youths' Participation in Agricultural Production in Oyo State: Panacea to Agribusiness Development in Nigeria,Pp 914-918

[4] Agumagu, A.C., Ifeanyi, O.C.C, Agu,C.(2017) Perception of Agriculture Students Toward Farming as Means of Sustainable Livelihood in Rivers State, Nigeria .Agricultural Extension Society of Nigeria, Pp 99.

[5] Agriculture, Sector Update (2019).Five Major Problems Facing Agriculture in Nigeria. Retrieved on 17/03/2020 from https://www.commodity-port.com/five-major-problems-facing-agriculture-in-nigeria/

[6] Agwu, N. M., Nwanko, E. \&Anyanwu, C. (2014). Determinants of Agricultural Labour Participation among Youths in Abia State, Nigeria. International Journal of Food and Agricultural Economics. 2(1) 157-167

[7] Adekoya, A. (2017).Economic Diversification: Youths and Agriculture, Retrieved on 13/2/ 2018 from https://tushmagazine.com.ng/economic-youths-agriculture/

[8] Agbonlahor, M. U., Oluwafemi, S. E., Sodiaya, C. I., Oludare, A. \&Oke, J. T. (2012). Accelerating Rural Growth Through Collective Action: Groups"e Activities and Determinants of Participation in South-Eastern Nigeria. Journal of Rural Social Sciences, 27(1), 114-136.

[9] Amungwa, F.A \&Baye, F.M. (2014).Asian of Agricultural Extension System. Asian journal of Agricultural Economics and sociology.2 (2), 530-543.

[10] Aliyu, A. B. \& Alfred S.I. (2017).An overview of social media uses in agricultural extension service delivery. Journal of Agricultural Informatics, 8(3), 50-61 
[11] Anaeto, F.C., Asiabaka, C.C., Ani A.O. \&Okoroma, E. O. (2015). Up -Scaling and Re-Branding Agricultural Extension Service in Nigeria: policy issues, options and challenges. International Journal of Advance Agricultural Research, (3), 10-16.

[12] Amungwa, F.A \&Baye, F.M. (2014).Asian of Agricultural Extension System. Asian journal of Agricultural Economics and sociology, 2 (2), 530-543.

[13] Ashley, C. (2019). Rational Choice Theory. Retrieved on 6/1/18 from https://www.thoughtco. com/rational-choice-theory-3026628

[14] Bhalchandra, B \& A Deshmukh (2017). A Study on Role of Social Media in Agriculture Marketing and its Scope.Journal of Management and Business Research: E Marketing, 17(1), 33-36

[15] Fabinu I (2014).Examining the impact of social media on Nigeria youth https://peoplesdailyng.com/ examining-the-impact-of-social-media-on-nigeria-youth/

[16] Food and Agriculture Organization of the United Nations (FAO) (2017). Research and Extension. Retrieved on August 02, 2018. http://www.fao.org/ nr/research-extension-systems/res-home/en/

[17] Guanah, S.J., Egbra, O.I., Omedomero, S. \&Akumabor, N.T. (2017). Social media, Youth and Agricultural Development in the Niger Delta Region of Nigeria.International Journal of Communication. Pp26-42,

[18] Guest, W. (2015). Can Technology Entice Youth to be Farmers? Retrieved on October 2017 from https://www.ictworks.org/can-technology-entice-youth-to-be-farmers/

[19] Irungu, K. R. G, Mbugua D \&Muia, J. (2015). Information and Communication Technologies (ICTs) Attract Youth into Profitable Agriculture in Kenya. East African Agricultural and Forestry Journal, 81(1), 2433

[20] Jacob U. A., Oshega, A. \&Ugor, O. E. (2017). Strategic Media Advocacy in Enhancing Sustainable Economic Development Through Active Youth' Participation in Agriculture in Nigeria International Journal of International Relations, Media and Mass Communication Studies ,3(5), 14-15

[21] Jasmine, K. M, Cleary, D. Grant N Herron, A Jumbo, S. Lacey, T Livingston, T Robinson, S Smith, R and Emanuel, E. (2016). What social media sites do college students use most? Pp 20-25

[22] Kayode, Adedeji, k.\&Agwu (2015). Application of ICT to Agriculture as a Panacea to

[23] Unemployment in Nigeria.International Journal of Advanced Multidisciplinary Research and Review, 3(4), 26-43.

[24] Khan, A. Rahman, A. Qazi, L. (2016). The Relationship Between Internet Usage, Socioeconomic Status, Subjective Health and Social Status.Bussiness \& Economic Review, 8, 69

[25] Kipkurgat, T, Onyiego, M \& S, Chemwaina, S. (2016). 'Impact of Social Media on Agricultural Extension in Kenya: A Case of Kesses District' International Journal of Agricultural Extension and Rural Development Studies, 3(1), 30-36.

[26] Khou, A \& Suresh, R. (2018). A Study On the Role of Social Media Mobile Applications and Its Impact On Agricultural Marketing in Puducherry Region. Journal of Management, 5(6), 28-35

[27] Lauren M, Sarah B and Dan D. (2014).How to Use Social Media for Your Farm Business, Pp, 7-8. https://poultry-science.uark.edu/SocialMediaWorkbookOnlineVersion.pdf.

[28] Muktar, B.G, Mukhtar, U \&Ahungwa, G.T. (2015). 'Harvesting Youth for Agro-Entrepreneurship: Stimulus Role of Social Media in Nigeria.' International Journal of Applied Research and Technology, 4(11)328-331.

[29] Ogbalubi, L. N \&Wokocha C.C. (2013).Agricultural Development and Employment Generation: The Nigeria Experience. Journal of Agriculture and Veterinary Science 2(2), 60-64

[30] Okiror, J.J \&Otabong, D. (2015). Factors Influencing Career Choice Among

[31] Undergraduate Students in an African University Context: The Case of Agriculture Students at Makerere University, Uganda. Journal of Dynamics in Agricultural Research,2(2),12-20 http://www.journaldy namics.org/jdar.

[32] Orifah, M. O. Ijeoma, M. C. Olajide, B. R. \&. Wigwe C. C (2017). Use of Social Media by Agricultural Undergraduate Students in Selected Universities in Nigeria.Journal of Agricultural Extension,21 (2) 124.https://dx.doi.org/10.4314/jae.v21i2.

[33] Paisley, C. (2013). Engaging Youth in Agriculture: Investing in our Future. Global Food for Thought. The Official Blog of the Global Agricultural Development Initiative.

[34] Retrieved May 18, 2018 http://globalfoodforthought.typepad.com/global-foo for Thought/2013/02/ Commentary-Engaging-Youth-in-Agriculture-Investing-in-our-Future.html. 
The Usage of Social Media in Engaging Youths in Agricultural Development in the Federal Capital Territory, Abuja, Nigeria

[35] Quickonomics (2018).Utility: Meaning, Characteristics and Types | Economics, Retrieved on June, 2018 from https://quickonomics.com/the-four-types-of-economic-utility.

[36] Suleiman M.M., Ogakason, R.O. \&Faruk N.B (2018).Influence of Social Media in Promoting Farmers' Participation in Agriculture.Nigerian. Journal of Agricultural Extension, 19(1),58-62

[37] Young Professionals' Platform for Agricultural Research for Development (YPARD). (2017). 9 Ways to Engage Youth in Agriculture.Retrieved on 11 April 2019 from https://ypard.net/news/9-ways-engageyouth-agriculture.

Citation: Alabi, T\& Nnaji, N, J. (PhD) "The Usage of Social Media in Engaging Youths in Agricultural Development in the Federal Capital Territory, Abuja, Nigeria" International Journal of Humanities Social Sciences and Education (IJHSSE), vol 8, no. 9, 2021, pp. 99-108. doi: https://doi.org/10.20431/23490381.0809010.

Copyright: (C) 2021 Authors. This is an open-access article distributed under the terms of the Creative Commons Attribution License, which permits unrestricted use, distribution, and reproduction in any medium, 